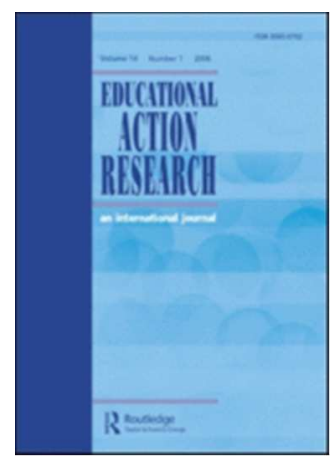

\title{
Collaborative action research through technologically mediated agoras.
}

\begin{tabular}{|r|l|}
\hline Journal: & Educational Action Research \\
\hline Manuscript ID & REAC-2014-0067.R2 \\
\hline Manuscript Type: & Accounts of Action research and development Studies \\
\hline Keywords: & $\begin{array}{l}\text { collaborative action research, information and communication technology, } \\
\text { initial teacher training, innovation, junior researchers, agoras }\end{array}$ \\
\hline
\end{tabular}

SCHOLARONE ${ }^{\text {Ix }}$

Manuscripts

URL: http://mc.manuscriptcentral.com/reac Email: ear@nottingham.ac.uk 


\section{Collaborative action research through technologically mediated agoras.}

The study presented here forms part of a wider project promoting collaboration between junior researchers from different universities with the objective of rethinking and improving teaching practice in relation to the use of technology. This paper describes research carried out during the 2012-2013 academic year aimed at developing collaborative action research through technologically mediated agoras involving students from three Spanish universities. The main results of this study show that junior researchers improved their teaching practice through technologically mediated inside and outside agoras. In addition, the transformation of university classrooms into agoras enabled the negotiated reconstruction of knowledge for the analysis of good practice in the use of technology. Likewise, these agoras helped reduce limitations by breaking down the barriers of time, distance and resources for sharing findings and limitations between junior researchers. Furthermore, they pave the way for improvements and their implementation in learning processes during initial teacher training.

Keywords: collaborative action research; information and communication technology; initial teacher training; innovation; junior researchers; agoras 


\section{Introduction}

Our training as junior researchers, belonging to the Educational Technology University Network, known as RUTE in Spanish, has enabled us to encourage the questioning of teaching practice and adopt a critical approach to the use of information and communication technology (ICT) in university classrooms. Primarily, this network seeks to look beyond the mere integration of technology into classrooms without question with the aim of encouraging the transformation of teaching practice through sharing concerns and research experiences in annual meetings. In addition, it encourages research on improving initial and on-going teacher training in the use of technology, analyzing the impact of educational policy in Spain. Within the framework of this network we were granted a subsidy in 2012 for our research project focused on the improvement of university teaching through the use of ICT. This work context has led to further training in research methods of three teachers from the different Spanish universities that participated in this project: the University of Cantabria, the University of the Basque Country and the University of Extremadura.

The Educational Technology University Network has provided us with the ideal circumstances for collaborating and strengthening professional relationships in our process of improving teaching and research. As a result, we have been able to develop action research aimed at generating a work context for promoting the exchange of experiences between junior researchers from different universities and for sharing our thinking on the use of ICT. The main points that form the basis of our action research are described below.

Firstly, our project arose from the need to start a process of teacher collaboration in relation to the design, development and assessment of principles of procedure in the use of technology in university classrooms, responsible for guiding and transforming the actions of the university teachers involved. Within an action research framework, taking into account the substantial contributions with regards to the teacher as a researcher (Stenhouse 1975, 1985; Elliot 1987, 2009; Carr 1980, 1986, 1987, 2005), principles of procedure constitute an alternative option from a reductionist view of a teaching model driven by the achievement of objectives focused on the academic performance of students. Through the establishment of principles of procedure teachers can specify educational objectives with an emphasis on action derived from reflection on practice. Principles of procedure are not learning objectives given that they are formulated by teachers in attempt to be both clarifying and reflective, in other words they are not formulated by an external body unrelated to teaching. In addition, theoretical principles and interrelated practices are formulated and revised in-depth thereby establishing value criteria and options with regard to teaching practice (James 2012). Thus the emphasis of these depends more on the actions of the teacher than on the achievements of their students.

The adoption of shared principles of procedure in the use of technology in our classrooms would allow us to guide educational practice and lay the foundations for collaboration on the innovative use of ICT in university teaching. However, a problem exists in that the mere use of technology in the classroom does not necessarily lead to innovation but instead it reinforces the teaching-learning model that underlies educational practices. As demonstrated in previous studies [Name deleted to maintain the integrity of the review process], despite expectations generated in relation to the transformational potential of technology, international and national research carried out in this area shows that the widespread use of ICT in schools has not led to significant changes in teaching practices (Law, Pelgrum, and Plomp 2008; Law, Yuen, and Fox 2011; Sancho and Correa 2010; Sola and Murillo 2011; Area et al. 2014). It is important to encourage the review and questioning of teaching practice with regard to 
introducing improvements, avoiding the passive adoption of externally imposed models. Teachers should be given the lead role in the management and administration of this change.

In our establishment of the principles of procedure, we consider it a priority to chart a course so that students can be trained from a critical perspective of the use of ICT, optimizing channels of communication as well as the relations between different agents and contexts. Therefore, it is necessary to point out that the use of the different tools selected (social network systems, blogs), described in the next section, follow a theoretical model in order to optimize the relationship between these contexts. In contrast a reductionist point of view of technology aims to divert attention away from technological aspects to focus more on pedagogic concerns related to the use of technology (Gao, Luo, and Zhang, 2012; Manca and Ranierit 2013).

As teachers, we are seeking to generate a context of reflection on the use of ICT in university classrooms, questioning the functionality of experiences and the role of tools in the critical multi-literacy of students, that is, we want to give students the ability to interpret information critically as well as produce it creatively in a technologically mediated context. This implies creating learning environments where the activity of the participants as providers of information in multiple languages such as sound or vision, are promoted. Thus we provide opportunities for them to manage critically and independently in the society in which they are immersed (Somekh 2007; Gutiérrez Martín 2008; Cloutier 2010).

Secondly, in our project we have made a commitment to improving the dynamic reconstruction of knowledge as well as increasing the openness of our own classrooms through the setting up of agoras. From a critical curricular perspective, where the contextualization and functionality of educational experiences are given priority, we proposed the creation of agoras or debates in which students must externalize their implicit ideas on educational innovation, take decisions to challenge their views and substantiate their arguments on the basis of the documentation produced (Wang, Bruce, and Hughes 2011). Setting up agoras enables the start of a process of transforming the university classroom into a meeting place based on equality for discussing problems and resistance to change in the school. In addition to setting up agoras we sought to move into different scenarios in order to encourage an interrelationship between educational contexts as a result of technological mediation.

Aware of the need to bring educational practice closer to students, we prioritized conducting debates in the classroom focused on real experience and research in order to encourage participants to question current teaching methods. It was considered that the use of ICT in classrooms offered the best context for reviewing the research role of teachers and the development of good practice: those initiatives that appeared capable of providing a different way of thinking and proceeding in order to improve creativity, flexibility and cooperation in curriculum development (Landow 2002). Likewise, these debates could provide an excellent opportunity for promoting links between initial and on-going teacher training. In short, with the generation of these spaces we are seeking to establish a suitable context, not only for enabling the transformation of our university teaching practice and the improvement of our students' learning experience but also for the generation of knowledge in the course of the designed actions (Denzin 2006).

\section{Design and development of the action research process Aims}

In our action research the following objectives were defined: 
- To reflect on the role of ICT in university teaching, through a process of shared design based on common principles of procedure in the use of technology.

- To share spaces so that students can debate on good practice in relation to the integration of technologies, transforming university classrooms into agoras.

- To improve the process of collaboration between participants.

\section{Context and phases of the action research}

This project has arisen from the need to generate and consolidate a work context aimed at encouraging the sharing of experiences between junior researchers from different universities. In 2012, the Educational Technology University network granted us a subsidy for a research project for reflecting on the improvement of university teaching through the use of ICT. Thus, we began a process of collaborative action research in which we are currently involved. However, although this process takes place over two phases, this paper presents the results analyzed so far, corresponding to phase I (first phase).

The first phase was developed during the 2012/2013 academic year in the Schools of Education in the University of Extremadura, the University of the Basque Country and the University of Cantabria. Three teachers from the area of Didactics and School Organization from three Spanish universities participated in this study together with their Pre-School and Primary Education students who were studying different subjects.

The participating students were different in the two semesters, therefore we refer to a fairly large sample in relation to: their experience at university (first or second year students), the course they were studying (Pre-school or Primary Education) and the subjects involved in their studies. Although the initial sample of participating students was high (first semester 230 students and second semester 354), it was considered that student collaboration could be voluntary in some activities while in others it would be compulsory. The difference between participating or not in the proposed activities depended on accessibility to social network systems outside a formal or academic context. The design synthesis of the phases and the context of the research are shown in Figure 1. Likewise, this figure shows the stages that will be described in detail in the next section (planning the action, implementing the plan, review and expansion stage).

[Figure 1. Participants, phases and stages]

\section{Data generation and collection}

Various methods related to the concept of technologically mediated qualitative methodology were used for data generation and collection. On the one hand, e-research methods were used by our students for data collection, such as tracking blogs and the observation of multi-media activities. In addition, face to face discussion groups took place at the end of the academic year with the aim of analyzing, evaluating and assessing the experience. Students who had been especially involved in the collaborative tasks with their peers, from other universities or external assemblies, participated in these discussion groups as will be explained in the following section.

On the other hand, for data collection on the process of reflection by teachers we mainly used the observation of our activities in the classroom, the analysis of documents generated in different phases of the process and focus groups which took place synchronously using both face to face and on-line meetings through video conferences as well as asynchronous meetings through forum discussions. A description of the tools used for the generation and collection of information are included in Figure 2. 


\section{Data analysis}

Categorization was carried out deductively following experimentation and the development of activities based on the categories defined in the face to face meeting (shown in figure 2). Briefly, these were the categories proposed for further analysis:

- Critical multy-literacy: The ability to use different tools to analyze and produce information independently, creatively and critically in the social context of reference (Gutiérrez Martín and Tyner 2012; Kendall and McDougall 2012).

- Collaborative work: This refers to group autonomy and maturity in relation to the different activities carried out. It also covers the analysis of aspects related to time management, positive interdependence and group cohesion (Kagan 1994; Johnson and Johnson 2004).

- Construction of knowledge: It is considered that aspects such as pre-conceptualization, awareness of their learning process, learning experiences, level of in-depth study, the dissemination of knowledge (with spontaneous and guided proposals) and the extrapolation of knowledge are fundamental for the analysis of the construction of knowledge (Wang 2007; Wang, Bruce, and Hughes 2011).

- Pedagogical relationship: In university and non-university educational contexts characterized by multidirectional interaction which is increasingly horizontal, the pedagogical relationship between student and teacher needs to be analyzed in order to encourage innovation in teaching (Sancho and Hernández 2013; Yang and Wang 2013).

- The development of principles of procedure: This involves specifying what the ideas are which form the basis of the use of technology, the definitions of teaching and learning that prevail and what is understood by innovation in teaching are essential for making sense of established practices and improving teaching practice (James 2012).

- Reflection on improvement: The review of practice is a key aspect in the action research process. Continuous reflection on the improvement of the process through structured monitoring enables the introduction of relevant adjustments in the face of identified difficulties (Elliot and Yu 2013; Elliot 2015).

It should be noted that the first four categories are related to practices designed by teachers and their impact on the experience of students. We consider the last two to be exclusively related to the work carried out by teachers in relation to the general project and to some of the aims of the research. In this paper we have focused on the analysis of the categories directly related to improving action research, in other words, to improving the reflection of the teachers involved and the process of transforming their own practice.

[Figure 2. Generation and code data]

\section{Reflection on the action research process}

The analysis and results obtained from our research are directly related to the stages and activities developed during the academic year. In the following section each of these stages will be explained in detail with an analysis of the activities developed as well as the use of tools in each one, reflecting on the process of transforming the practice of junior researchers.

\section{Planning the action}

Our starting point was shared reflection on the use of ICT in university teaching. In planning the process of collaboration, based on the theoretical foundations established in the previous 
section, we began the process of sharing and analyzing existing good practice with the aim of questioning teaching methods through a technologically mediated process using different languages and media.

Firstly, we began with the creation of a website to facilitate sharing information on the design of our classroom practices, the project initially negotiated, the literature review and the analysis of good practice mentioned earlier. We also identified the need to complement this static tool with a dynamic tool which would facilitate communication between junior researchers. For this we chose the use of a forum as a place for designing activities through negotiation, reflecting on the obstacles and difficulties identified in process monitoring meetings as well as the experience of collaborative work between our students.

Once the areas of exchange had been defined we embarked on a process of reflection on the use of technology in the classroom in relation to some principles of procedure with the aim of guiding and transforming our teaching practice. To this end, individual reflection and further on-line discussion took place to jointly negotiate our role as facilitators of student learning in general and more specifically as mediators of the critical vision on the use of ICT, in particular. Our initial reflections were aimed at explaining the essence of a critical approach which would enable us to guide the process of change: How can the use of technology be improved? What areas and tools can we use to transform our classrooms? How can we break down classroom barriers and expand into other contexts? In short, it related to a common consensus framework which would guide our collaborative process of transforming technologically mediated teaching practice, as demonstrated in the following example where junior researchers (named in the quotations as R1, R2, R3) discuss the formulation of the principles of procedure.

R1: We could tell students to collect information on what they consider to be good practice, in order for them to tell us about good practices they experienced during their period of compulsory schooling (...) we could think about establishing a principle of procedure in the following way, for example: In the classroom together with students, we will rebuild knowledge about technology in teaching, thereby creating common meanings.

R2: I'm not sure. I think it's a bit abstract, maybe we should be more specific about the principle, we should mention that it will be about good practice. What do you think? [Forum discussion transcript 19/09/2012]

Following initial discussion about the principles of procedure, we wrote a progress report in order to outline the framework of action based on shared, critical and creative views on the use of technology in teaching and research. This common framework for action allowed us to outline a common way forward; we agreed to introduce reflection on practice through monitoring determined actions and questioning the role of technology in the transformation and improvement of our performance in the classroom. The use of ICT and the integration of this into teaching as part of the process of educational innovation require research and the analysis of tools and practices. Therefore it is essential to be able to design and experiment with activities which serve to help not only students but also teachers in order to direct the process of improvement appropriately. The results of our reflection on principles of procedure (in italics) are summarized below:

- There will be a shared critical vision of the use of technology which must permeate inter-university collaboration: This enables practice in university classrooms capable of exercising understanding, reflection and communication using different languages and media, thereby contributing to the multi-literacy of students.

- Knowledge will be rebuilt jointly with students creating common meanings through shared areas of analysis of good practice, providing new ways of thinking and acting: 
We will try to break down the barriers of the university classroom to enrich experiences in relation to technological mediation. In this regard we will be able to jointly reconstruct our subjects through dialogical action.

- Bridges will be built between universities and schools and between educational theory and practice: This means prioritizing activities so that students can explore the relevance of the research in teaching performance through the use of ICT. The participation of teachers from different levels of education and from different geographical contexts will be encouraged.

- Expansion, mixing contexts and the dissemination of experience will be pursued: The dissemination of our experience should be established as a first step for promoting the expansion of our project; we need to strengthen the foundations for an inter-university learning network sustainable over time by increasing participation.

\section{Implementing the plan}

The planning stage was concluded with the design of agoras as areas to be reinvented in each university classroom, to enable the transformation of the normal dynamics of the one-way transmission of knowledge in university classrooms through the use of technology, diversifying the arrangement of working areas and enriching the exchange of knowledge between participating universities.

The work forums from our on-line scenario were used to implement dialogic action, where varying levels of depth of content in relation to the practices analyzed were produced. At the same time these forums enabled both the transmission of the collection and analysis of information as well as the introduction of appropriate adjustments in the design. This can be seen in the quotation below, where one of the junior researchers reflects on the need to introduce modifications in the use of the forum in order to improve data generation and collection according to the type of agora which has taken place:

R1: If you agree, we'll leave the other topic for "inside agoras", that is, the collection of experiences that we have in class, and we'll use this new line of conversation for the "external agoras", in other words, what we are going to share externally both in the long and short term. We had considered the possibility of creating an area for exchanging good practice in the use of ICT among our students (...) [Forum discussion transcript 14/10/2012]

\section{Inside agoras}

During the first semester we held what we call inside agoras. Following the individual review of the subject contents by students, we encouraged joint decision making in small groups and, subsequently, combined the group-class through collective assemblies. Basically through carrying out these debates, enriched by the use of ICT, we achieved the negotiated reconstruction of knowledge. Thus we managed to convert the classroom into a laboratory of confrontation of perspectives in order to reflect on subject contents, that is, we created agoras to explore intuitive knowledge or student experiences related to good practice in education.

Furthermore, the inside agoras, as practices designed in each university classrooms, included technologically mediated activities developed individually in this university classroom, for example Twitter, following the viewing of films or the preparation of eportfolios for the purpose of sharing discussion on the evidence of learning over the course of the subject.

Nevertheless, reflection on the design and development of the activity was shared by junior researchers as a result of the dialogic action of the forums, so that collaboratively and beyond 
the context of the classroom, the improvements could be identified. It is important to point out the fruitful support process and improvement between teachers participating in the experience. The dialogic action of the forums enabled rebuilding and enhancing individual experiences, as well as overcoming difficult moments. In short, although the agoras took place in one university classroom, they were echoed and improved thanks to our joint reflection in the forum. In the following quotation a junior researcher (R1) shares their reflections on the educational meaning of an activity carried out in the classroom in order to encourage the identification of different curricular approaches in educational practice and analyze the option of a critical curricular focus. The participation of other junior researchers ( $\mathrm{R} 2$ and $\mathrm{R} 3$ ) enables the reconstruction of the meaning of the activity as can be seen in the following extract:

R1: We had arranged to share reflections about curricular approaches to the film "It all starts today (Tavernier, 1988) via twitter, but then I had some doubts, to the point where I decided to completely stop before launching the activity. A lot of the students told me that the film was too slow, that it had been really boring...so I stopped because the idea of leaving a negative footprint on-line with negative comments like that...I feel blocked and haven't been able to find a solution yet... Do you think I should restart? Now we are in the final stages, summarizing....could we reconsider it?

R2: It's a good idea to stop and think about what we are doing, what our objective is (...) We need to take into account that we are using twitter in an educational and innovative way for most of our students, so we have to get used to this educational use and above all focus participation on recreating critically.

R3: I agree with R2 on the need to explain the potential this tool has for creating, sharing and distributing knowledge and information; show them networks and professional educational groups that learn and exchange on-line. Greetings and let's carry on! [Forum discussion transcript 10/12/2012]

\section{Outside agoras}

During the second semester what we call outside agoras were developed: discussion areas for inter-group participation, that is, between students from participating universities, jointly beyond the activities proposed in each university classroom, either synchronously or asynchronously. Joint reflection on development through the face to face focus group through video conferences enabled us to share the main difficulties encountered in this development, as well as adapt our wide-ranging aims and expectations to time constraints. But above all, it enabled us to divert attention away from technology to focus more on how to improve our own performance to ensure that a critical view of technology would be transferred to students. It was necessary to emphasize their research role as future teachers, the questioning of the underlying focus on practices or on actions to be carried out in the short term in order to encourage curricular development or innovation. One researcher (R3) referred to their critical perspective, reflecting on outside agoras in the forums:

R3: (...) some of the contributions were repeated and I noticed that many students go along with the same thing and tweet about what they hear or understand. That is, not many students read or offer other types of comments or even ask questions. [Forum discussion transcript 13/03/2013]

On the one hand, some of the outside agoras devised arose from exchanges between the agoras which took place internally in the remaining universities participating in the project. This related to the search for the echo of the activity initially devised internally, replicating experiences in order to see the effects on other university contexts and thus contributing to 
providing greater depth to the debate as well as increasing the resonance and participation initially obtained with regard to this, as the following quotation demonstrates.

R3: To finish the week, I received some really good news on entering the classroom. In my class three of the groups had already received comments from yours, R2: one group had received 14 comments and another is still waiting because they haven't received anything yet and they are really worried about it. [Forum discussion transcript 14/04/2013]

On the other hand, external agoras were developed beyond the context of the university, encouraging openness in university spaces and their relationship to the reality of schools. As we advanced, we felt the need to incorporate other voices into the classroom and we began the analysis of educational practices outside the context of university classrooms where students could discuss the underlying problems related to these practices, thus contributing to the dissemination and use of good practice or innovative educational experiences in schools and experimentation with the teacher researcher role. Beyond the mere use of technological tools, as we will demonstrate in the following section, it is important to point out the implications of shared reviewing and monitoring in the transformation of our individual practices as well as the evolution and improvement of our process of collaboration.

\section{Review and expansion stage}

The primary objective of the dissemination phase was to rethink the role of ICT in our process of collaboration, transformation and improvement of practice and its role in continuous reflection on action. In addition, the process of expansion towards other scenarios and contexts, awareness of the difficulties and improvements to be developed for the new cycle of action should also be highlighted in its development, through forum discussion:

R1: Creating, expanding horizons...proposing further action, new goals...Establishing new areas for work, proposals for action...but these need to be sufficiently flexible and open to allow creativity, the incorporation of new elements, growth, exchange... time, the tools and the areas used should facilitate merging oneself with the "Other", with what I have been thinking, reading, experimenting, experiencing...to create an "Us-other " (me with the Others). This is possible thanks to more open ideas, more interested in the purpose of learning (what we want ourselves, as a group) on this journey, without the permanent obsession for the final product and/or time-space constraints that sometimes leave their mark on schedules. [Forum discussion transcript 10/05/2013]

A significant milestone in this phase was the setting up of a face to face meeting to enable the generation of a scenario which goes further than the potential of ICT in teacher collaboration. It reflected on all the experiences, individual conflicts, and dilemmas of the university environment together with our situation as junior researchers using a technologically unmediated area as a setting for this.

We also reviewed the possible scenarios and communities of practice where we could share our experiences with the aim of disseminating the findings together with the experience of the innovation developed through the project. In the process of decision making the limitations of junior researchers in disseminating knowledge became apparent. While experiencing the need to share and expand, the constraints of the Spanish university system in relation to methods of accreditation or the internal promotion of junior researchers prevents us from disseminating our experience without securing recognition through publications. As some research and studies in Spain demonstrate, while the production of knowledge is common in a competitive context it is not always possible in a collaborative one (Escudero et al. 2010; De la Herranz and Paredes 2012). Nevertheless, our commitment to expanding our 
network in order to nurture sharing experience, advancing and improving in collaboration with others has led us to prioritize the need for openness and visualization in an on-line setting. Furthermore, as we progress in the process of diffusion we continue to share our achievements, findings and controversies in wider contexts such as the Spanish network we belong to.

Finally, we took advantage of these meetings in order to outline the foundations for the next cycle of action, based on identifying the main difficulties of the process as will be explained in the following section.

\section{Findings and limitations}

Action developed jointly has made furthering the objectives of the research possible.

Firstly, it was necessary to negotiate a starting point so that the action designed would be based on theories and broader pedagogic ideas with the ultimate aim of being able to generate knowledge based on reflection on action. Establishing principles of procedure has enabled us to start from a joint review of the role of ICT in the transformation and improvement of our teaching. The results of our research demonstrate how experiences are articulated using our own practice as a focal point for reflection as well as the use of technology in initial teacher training in other university contexts. Thus we have succeeded in prioritizing a common vision of the selection of some tools accompanying, from a critical perspective, the exchanges, reflection, contact and distribution of information by students who participated in this experience (Ampartzaki et al. 2013). This has enriched their learning process both as future teachers and as students. In addition to experiencing in first person the benefits of collaborating with others firsthand, despite distances and different personal and cultural situations, this shared vision has enabled them to find a model of technologically mediated collaborative reflection among university teachers (Selwood and Twinning 2008; Twinning et al. 2013).

Secondly, we have succeeded in developing a scenario for carrying out research rethinking the university classroom, generating agoras or practices through the use of ICT for the analysis of good practice in the use of ICT. Collaboration between teachers has enabled the design of training activities with the aim of innovation in teaching methodology generating and experimenting with new curricular formulas and methodologies (Landow 2002).

We believe it is necessary to experience the use of technology as a means of encouraging the transformation of university classrooms, diversifying groups and promoting openness. On the one hand, the exchange of practices generated has enabled shared reflection on the improvement of our own teaching. On the other hand, we have succeeded in opening the classroom to other university classrooms, and encouraging the questioning of standardized models of teaching where text books orchestrate the submission of teachers and in which the divergence of organizational models of school reality or establishing different models between knowledge and subjects is hardly accommodated (Pérez-Gómez et al. 2009; Prieto et al. 2011). Thus we have sought continuity and extra-polarity with curricular activities in different university contexts, taking advantage of the work carried out by students to design good practice as a basis for methodological innovation in university teaching. This good practice accompanied by ICT has been focused at all times on improving teaching and learning by students.

Finally, we have succeeded in making a firm commitment to joint collaboration as junior researchers in order to consolidate an inter-university community of practice in the future, with the objective of making contributions based on the transformation of our own practice. Action research is an effective professional development strategy for collaboration and 
networking (Salm 2013; Zehetmeier 2015). Initially we have been able to critically review the process together with other external networks, as a result of participation in wider contexts, in our attempt to increase collaboration and dissemination of knowledge. Although there is still a long way to go, we have tried to reflect on the controversies inherent in these processes (Herr and Anderson 2005; DePalma and Teague 2008; Somekh and Zeichner, 2009; Genevieve and Thomas-Spiegel 2013).

Nevertheless, the review process enables us to identify the main difficulties encountered in establishing our design. As demonstrated in previous studies (Kim 2013; Goh and Loh 2013; Sherab 2013) collaboration between students has enhanced the exchange of ideas, experiences and concerns, but not so much with regard to an in-depth debate of these ideas or concepts in the search for meaning and the joint construction of knowledge. In addition to the main difficulties identified, together with resistance to changing the way of working as a group, we found an excessive overload of tools which have contributed to dispersing students. Therefore, we believe that based on this first experience between ourselves as teachers and groups of students, the analysis of our educational models, planning the design of activities and the collaborative learning environment need to be improved.

Together with the difficulties encountered in the process of technological mediation, we detected the need to methodologically redesign our work environment in order to distance ourselves from the excessive secrecy and rigidity of previous planning cycles. Practices or work environments should not be designed like puzzles so that each piece fits into place perfectly because this implies that we already have a final picture in mind, a given answer, a carefully created route. On the contrary, we want to redefine collaboration and find a way so that pieces fit together through a negotiated process involving the participants because interests should be shared jointly and not imposed from outside (Cook 2014). In this way we will be able to progress and pave the way for new spaces for collaboration capable of promoting pedagogic events open to the uniqueness of what happens, fuelled by surprise and uncertainty in their own working context (Atkinson 2012).

Ultimately, we will continue to question ourselves on this new way forward with regard to enabling processes of change to take place, encouraging inter-university collaboration where possible. Thus creating a hotbed for developing ideas concerning how and why we should share in the pursuit of our teaching model through the process of action research.

\section{Acknowledgements}

We would like to thank the Educational Technology University Network, known as RUTE in Spanish, for the funding received for the development of this project. The project was coordinated by the University of Cantabria and researchers from the University of Extremadura and the University of the Basque Country under the title "Research Project for reflecting on the improvement of university teaching through the use of ICT".

\section{References}

Ampartzaki, M., M. Kypriotaki, C. Voreadou, A. Dardioti, and I. Stathi. 2013. "Communities of practice and participatory action research: the formation of a synergy for the development of museum programmes for early childhood." Educational Action Research, 21 (1): 4-27.

Area, M, C. Alonso, J.M Correa, C. Del Moral, J.P. Pons, J. Paredes, J. Peirtas, A. Sanabria, A. San Martín, and J. Valverde. "ICT education policies in Spain after School Program 2.0: Emerging Trends." Relactec, 13 (2):11-33.

Atkinson, D. 2012. "Contemporary Art and Art in Education: The New, emancipation and truth." International Journal of Art and Design Education, 31 (1), 5-18. 
Buela-Casal, G. 2007. "Reflexiones sobre el sistema de acreditación del profesorado funcionario de Universidad en España." Psicothema, 19 (3): 473-482.

Carr, W. 1980. "The Gap between Theory and Practice." Journal of Further and Higher Education, 4 (1): 60-69.

Carr, W. 1986. "Theories of Theory and Practice." Journal of Philosophy of Education, 20 (2): 177186.

Carr, W. 1987. "What Is an Educational Practice? Journal of Philosophy of Education, 21 (2): 163175.

Carr, W. 2005. "The Role of Theory in the Professional Development of an Educational Theorist." Pedagogy, Culture and Society, 13 (3): 333-345.

Cloutier, J. 2010. "Historia de la comunicación." In Conectados en el ciberespacio, edited by R. Aparici, 37-44. Madrid: UNED.

Cook, T. 2014. Minding our Ps and Qs: Participation and Quality In Participatory Action Research. Collaborative Action Research Network Conference: Connecting Researchers, connecting communities. Gateshead, UK.

De la Herrán, A., and J. Paredes. 2012. Promover el cambio pedagógico en la universidad. Madrid: Pirámide.

Denzin, N. 2006. Sociological Methods: A Sourcebook. Piscataway. N.J: Aldine Transaction.

DePalma, R., and L. Teague. 2008. "A democratic community of practice: unpicking all those words." Educational Action Research, 16 (4): 441-56.

Elliott, J. 1987. "Educational Theory, Practical Philosophy and Action Research." British Journal of Educational Studies, 25 (2): 149-169.

Elliot, J. 2009. "Building educational theory through action research". In The Sage handbook of educational action research, edited by S. Noffke and B. Somekh, 28-39. London: Sage.

Elliot, J. 2015. "Educational Action Research as the quest for virtue in teaching." Educational Action Research, 23 (1): 4-21.

Elliot, J., and C. Yu. 2013. "Learning Studies in Hong Kong Schools: A Summary Evaluation Report on the Variation for the Improvement of Teaching and Learning' (VITAL) Project." Education \& Didactique 7 (2): 147-163

Escudero, T., J. L. Pino, and C. Rodríguez Fernández. 2010. "Evaluación del profesorado universitario para incentivos individuales." Revista de Educación, 351: 513-537

[Reference deleted to maintain the integrity of the review process]

Gao, F., T. Luo, and K. Zhang, K. 2012. "Tweeting for learning: A critical analysis of research on microblogging in education published in 2008-2011." British Journal of Educational Technology, 43 (5), $783-801$.

Genevieve, G, and J. Thomas-Spiegel. 2013. "Action research for instructional improvement: the Bad, the Ugly and the Good." Educational Action Research, 21 (4): 468-484.

Goh, L., and K. Loh. 2013. "Let them fish: empowering student-teachers for professional development through the project approach." Educational Action Research, 21 (2): 202-218.

Gutiérrez Martín, A. 2008. "Participatory action research as a strategy for media literacy." In Participatory action research as a necessary practice for the twenty-first century society. CARN Bulletin, 13, edited by A. Gutiérrez Martín, and L. Torrego, 61-65. Manchester: Manchester Metropolitan University and CARN.

Gutiérrez Martín, A., and K. Tyner. 2012. "Media Literacy in Multiple Context". Comunicar, 38 (19):10-13.

Herr, K., and G. Anderson. 2005. The action research dissertation: a guide for students and faculty. Thousand Oaks: Sage.

James, M. 2012. "An alternative of the objectives model: The process model for the design and development of the curriculum." In Curriculum, Pedagogy and Educational Research: the work of Lawrence Stenhouse, edited by J. Elliot and N. Norris. London: Routledge

Johnson, D., and R. Johnson. 2004. Assessing students in groups. Promoting group responsibility and individual accountability. California: Corwin Press.

Kagan, S. 1994. Cooperative Learning. San Clemente, CA: Kagan

Kendall, A., and J. McDougall. 2012. "Critical Media Literacy after the Media". Comunicar, 38 (19):10-13. 
Kim, M. S. 2013. "Technology-Mediated Collaborative Learning Environments for Young Culturally and Linguistically Diverse Children: Vygotsky Revisited." British Journal of Educational Studies, 61 (2), 221-246.

Landow, G. 2002. Educational Innovation and Hypertext: One University's Successes and Failures in Supporting New Technology. In Silicon Literacies: communication, innovation, and education in the electronic age, edited by I. Snyder, 101-115. London: Routledge

Law, N., W.J. Pelgrum, and T. Plomp. 2008. Pedagogy and ICT in schools around the world: findings from the SITES 2006 study. Hong Kong: CERC and Springer. http://sites2006.ITCe.hku.hk/SITES2 2006-ITCE-Seminar080310.pdf.

Law, N., A. Yuen, and R. Fox. 2011. Educational Innovations Beyond Technology: Nurturing Leadership and Establishing Learning Organizations. SpringerLink: Bücher.

Manca S., and M., Ranierit. 2013. "Is it a tool suitable for learning? A critical review of the literature on Facebook as a technology-enhanced learning environment." Journal of Computer Assisted Learning, 29: 487-504.

Pérez-Gómez, A., M. Sola, E. Soto-Gómez, and F. Murillo. 2009. The impact of action research in Spanish schools in the post-Franco era. In Handbook of educational action research, edited by S. NoffKe, and B. Somekh, 481-494. Thousand Oaks, CA: Sage.

Prieto Santos, L.P., S. Villagrá, I. Jorrín, A. Martínez Mones, and Y. Dimitriadis. 2011. "Recurrent routines: analyzing and supporting orchestration in technology-enhanced primary classrooms." Computers and Education, 57 (1): 1214-27.

Salm, T. 2013. "Action research to improve collaboration among Student Support Services Team." Educational Action Research, 22 (1): 93-108.

Sancho, J. M., and J. Correa. 2010. "Change continuity in changing education systems." Educational Review, 352 (2): 7-21 [In Spanish].

Sancho, J., and F. Hernández-Hernández. 2013. "Developing Autobiographical Accounts as a Starting Point in Research." European Educational Research Journal, 12(3), 342-353.

Selwood, I., and P. Twining. 2005. Action research and ICT. Coventry: Becta. http://partners.becta.org.uk/index.php?section=rh\&\&catcode=_re_rs_pr_03\&rid=13468.

Sherab, K. 2013. Strategies for encouraging behavioural and cognitive engagement of pre-service student-teachers in Buthan: an action research case study. Educational Action Research, 21 (2): 164-184.

Sola, M., and F. Murillo. 2011. ICT in Education. Reality and expectations. Annual Report 2011. Barcelona: Ariel. Telefónica Fundation [In Spanish].

Somekh, B. 2007. Pedagogy and learning with ICT: researching the art of innovation. London: Routledge.

Somekh, B., and K. Zeichner. 2009. "Action Research for Educational Reform: remodelling action research theories and practices in local contexts." Educational Action Research, 17 (1): 5-21.

Stenhouse, L. 1975. An introduction to curriculum and development. London: Heinemann Educational Books.

Stenhouse, L. 1985. "The objectives model: some limitations." In Research as a basis for teaching: readings from the work of Lawrence Stenhouse, edited by J. Rudduck, and D. Hopkins, 75-79. London: Heinemann Educational Books.

Twining, P., J. Raffaghelli, P. Albion, and D. Knezek. 2013. "Moving education into the digital age: the contribution of teachers' professional development." Journal of Computer Assisted Learning, 29 (5): 426-437.

Wang, L. 2007. "Socicultural learning theories and information literacy teaching activities in higher education." Reference \& User Services Quarterly, 47 (2): 149-158

Wang, L., C. Bruce, and H. Hughes. 2011. "Hughes Sociocultural Theories and their application in information literacy research and education." Australian Academic \& Research libraries, 42 (4): 296-308.

Yang, H. and S. Wang. 2013. Cases on Online Learning Communities and Beyond: Investigations and Applications. Hershey PA: Information Science Reference

Zehetmeier, S., I. Andreitz, W. Erlacher, and F. Rauch. 2015. "Researching the impact of teacher professional development programmes based on action research, constructivism, and systems theory." Educational Action Research, 23 (2): 162-177. 


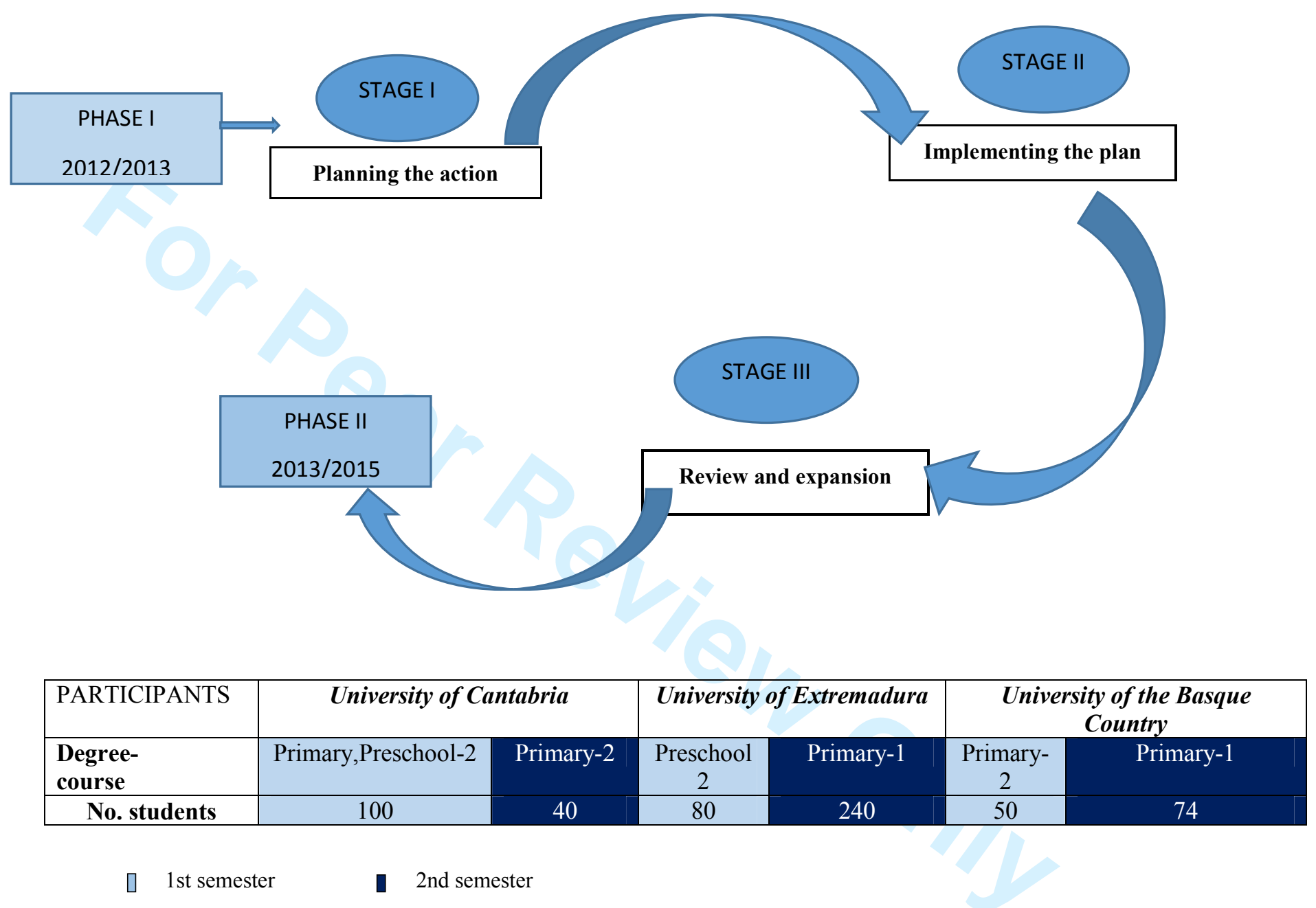

Figure 1. Participants, phases and code data. 


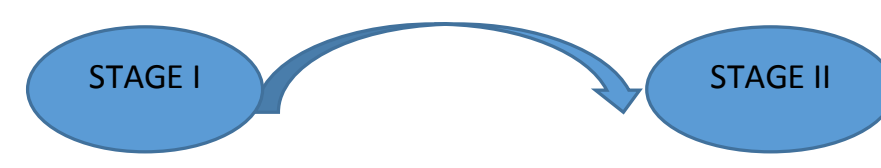

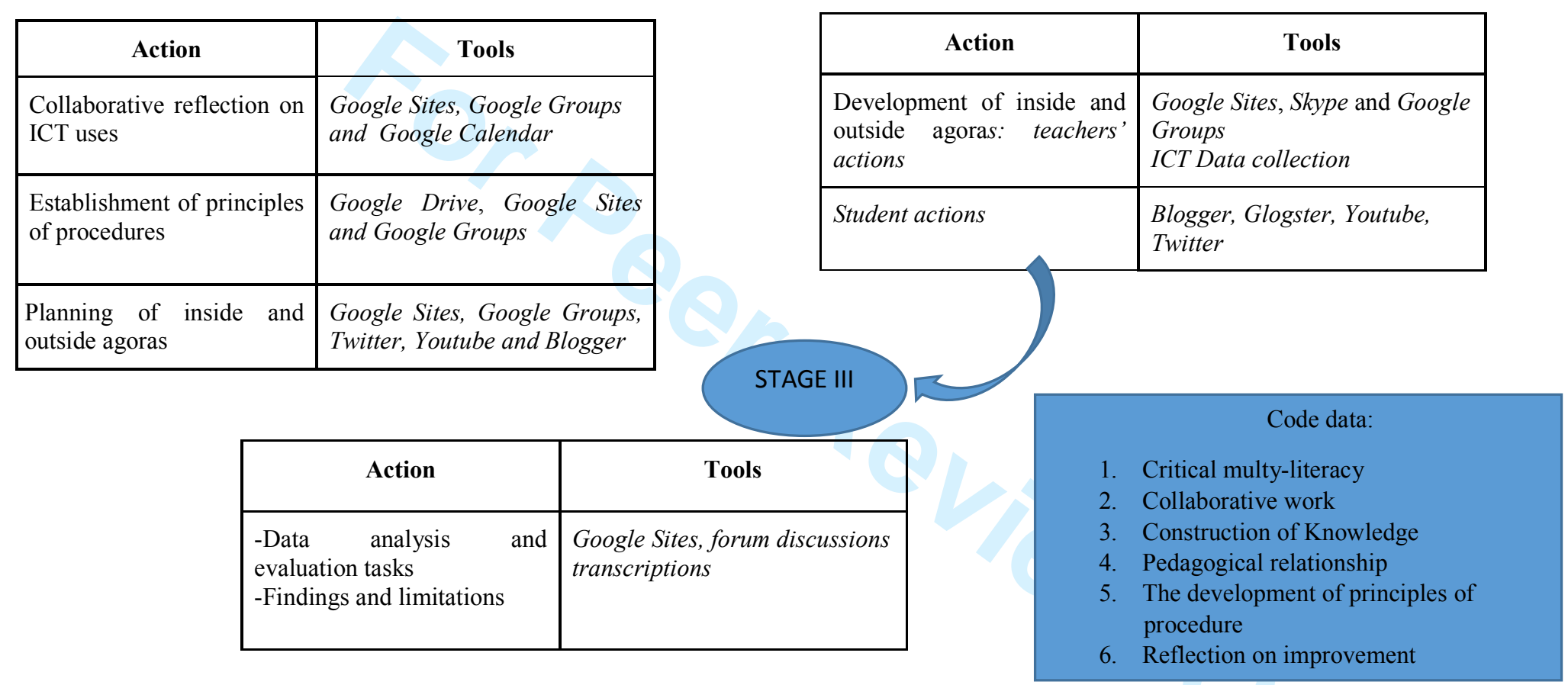

Figure 2. Generation and code data. 